\title{
As international as they would let us be
}

\author{
Virginia Trimble ${ }^{1,2}$ \\ ${ }^{1}$ Dept of Physics \& Astronomy, U. Calfornia, Irvine CA 92697-4575 USA \\ email: vtrimble@astro.umd.edul \\ ${ }^{2}$ Queen Jadwiga Observatory, Rzepiennik, Biscopi, Poland
}

Extended Abstract. Astronomers wanting to chart the whole sky, or even part of it, 24/7, must collaborate across nations, continents, and hemispheres. The Greeks were perhaps the first to do this, though Eratosthenes' measurement of the diameter of the earth was done when Alexandria and Syene were both part of Ptolemaic Egypt. The Golden Age of Arabic/Moslem astronomy coincided with times when there were very large caliphates and similar empire-like structures. The situation was very different for European astronomy at all times, with periods of successful international collaborations alternating with periods of disaster. Von Zach's "celestial police" agreed in 1800 at Lilienfeld to divide up the sky and look for the "missing" planet between Mars and Jupiter. The observatory was ransacked and papers burned by retreating Napoleonic soldiers in 1813. Skipping ahead most of a century, the Carte du Ciel, George Ellery Hale's Solar Union, Kapteyn's selected areas, and several other cooperative projects had scarcely started when the Great War broke out, and a German eclipse expedition under Erwin Freundlich, which had gone to the Crimea to look for bending of starlight, was imprisoned. All members eventually got home, but the equipment was never recovered.

While British eclipse expeditions organized by Eddington saw the bending of light from Sobral and Principe in 1919, the IAU, founded in the same year, explicitly excluded Germany, Austria-Hungary, Turkey, and the other central powers (even neutrals were not admitted for several years). Indeed Germany did not adhere until 1952. IAU membership now is generally driven by financial issues, but the solution of one nation, two adhering organizations for China was a major victory for international compromise. Coming down to the present, it is interesting that Europe, the site of the outbreak of both the World Wars, has led in the establishment of the European Southern Observatory, the European Space Research Organization (now ESA), and Astronomy and Astrophysics. Even the USA is gradually learning to cooperate with other astronomical nations (though we are still not brilliantly good at it). And the current projects for very large ground-based observing facilities, with acronyms like LOFAR, SKA, GMT, EVLT, and TMT, involve most of Europe, North America, China, Japan, India, and other parts of Asia and South America. A printed version of my FM2 presentation is in press for Vol. 43 (December 2015 issue) of the Journal of American Association of Variable Star Observers (roughly half of whose membership resides outside the US).

I thank Gudrun Wolfschmidt for a list of the astronomers who made up the "celestial police". 